\title{
Ensurdecimento de fonemas plosivos na fala de crianças disfônicas
}

\section{Devoicing of plosive phonemes in dysphonic children's speech}

\author{
Mirian Aratangy Arnaut ${ }^{1}$, Clara Regina Brandão de Ávila²
}

\begin{abstract}
RESUMO
Objetivo: Caracterizar a fala de crianças disfônicas, quanto à ocorrência de ensurdecimentos de fonemas plosivos. Métodos: Foram gravadas as repetições de frases de 50 crianças (idades entre quatro e oito anos), sendo 40 crianças disfônicas e dez, sem alterações vocais. Eram seis frases com os fonemas plosivos sonoros em sílaba tônica inicial, medial e final de palavras. Com as produções gravadas realizaram-se análise espectrográfica, pela identificação da barra de sonoridade e perceptivo-auditiva, por meio de uma banca de três fonoaudiólogas. Resultados: O ensurdecimento ocorreu de forma assistemática na produção dos fonemas sonoros, foi mais identificado à análise espectrográfica e variou conforme o fonema e a posição deste na palavra. Conclusões: Houve ensurdecimentos assistemáticos na fala das crianças disfônicas e sem alterações vocais, com menor frequiência na posição tônica da sílaba medial.
\end{abstract}

DESCRITORES: Fala; Distúrbios da voz; Distúrbios da fala; Acústica da fala; Criança

\section{INTRODUÇÃO}

Os fonemas são unidades sonoras abstratas que transmitem diferenças semânticas. Muitas vezes, a diferença de significados é marcada pela escolha de um fonema que se diferencia de outro por um único traço distintivo, como é o caso de palavras que se opõem pelo traço de sonoridade. Um dos fenômenos fonológicos mais interessantes a ser investigado é a relação que existe entre elementos totalmente abstratos, como os traços distintivos dos fonemas, e suas manifestações, que no sinal de fala revelam-se como pistas acústicas, algumas resultantes da vibração das pregas vocais, cuja ocorrência confere à fala sua característica de sonoridade ${ }^{(1)}$.

Algumas propostas de avaliação da voz podem fornecer dados sobre a produção dos sons articulados, pois contemplam, também, a análise dos mecanismos de articulação e o de ressonância, na investigação das características supralaríngeas da qualidade vocal ${ }^{(2)}$.

Da mesma forma, a avaliação da fala, levando em conta a possibilidade de haver alterações na produção, assim como na recepção ou, ainda, na organização mental dos sons lingüísticos ${ }^{(3)}$ mostra, a partir dessa concepção, o quão imprescindível é idealizar formas de avaliar a fala em sua completude e complexidade.

Trabalho realizado na disciplina de Otorrinolaringologia da Universidade Federal de São Paulo - São Paulo (SP), Brasil

(1) Mestre em Distúrbios da Comunicação Humana pela Universidade Federal de São Paulo - UNIFESP - São Paulo (SP), Brasil; Fonoaudióloga clínica São Paulo (SP), Brasil.

(2) Doutora, Professora Associada do Departamento de Fonoaudiologia da Universidade Federal de São Paulo - UNIFESP - São Paulo (SP), Brasil. Endereço para correspondência: Mirian Aratangy Arnaut. R. Joaquim Antunes, 232, Pinheiros, São Paulo - SP, CEP 05415-000. E-mail: m.arnaut@ terra.com.br

Recebido em: 27/6/2007; Aceito em: 29/2/2008
As características de produção da voz desempenham, assim, importante papel no processo de ensurdecimento de fonemas ${ }^{(4-6)}$.

O ensurdecimento é um processo fonológico que aparece em crianças, falantes do Português Brasileiro, em desenvolvimento fonológico típico, porém em idades muito precoces. Raramente aparece em crianças acima de três anos. No desenvolvimento típico, a correlação entre a idade e o processo de ensurdecimento é negativa, ou seja, quanto maior a idade, menor o aparecimento do ensurdecimento, e que este processo fonológico parece ser eliminado antes nos plosivos do que nos fonemas fricativos ${ }^{(7)}$. Dentre os processos fonológicos mais comumente encontrados em população de crianças com transtorno fonológico está o ensurdecimento de fonemas plosivos e fricativos ${ }^{(8)}$.

Não é raro observar crianças que apresentem alterações de fala e voz na prática fonoaudiológica.

Pesquisadores encontraram $86,7 \%$ de trocas, $80 \%$ de omissões e $43,34 \%$ de distorções na fala de crianças que procuraram atendimento fonoaudiológico com queixas exclusivamente de fala. Relataram a presença de características de alterações vocais em 50\% das crianças embora elas não trouxessem essa queixa $^{(4)}$.

Crianças com alterações de fala caracterizadas pelo ensurdecimento podem apresentar dificuldade no controle laríngeo. Devido a essa dificuldade tais crianças emitem um fonema próximo cuja produção, facilitada pela ausência de participação glótica, seria percebida como o correlato surdo ${ }^{(9)}$. Essa pesquisa mostrou que crianças que trocam sons sonoros por surdos apresentam frequiência fundamental mais baixa, produzem repetições silábicas mais lentamente e realizam repetições arrítmicas, indicando dificuldades no controle motor oral e glótico. A alteração da dinâmica vibratória das 
pregas vocais provoca vibrações aperiódicas e irregulares, decorrentes do desequilíbrio entre a tensão mioelástica e a pressão da corrente aérea subglótica ${ }^{(10)} \mathrm{o}$ que pode dificultar a pré-sonoridade ${ }^{(11)}$. Na infância, essas alterações da produção vocal são causadas, sobretudo pela presença de nódulos vocais, principal etiologia da disfonia infantil, cuja prevalência é de 6 a $9 \%$ na população ${ }^{(12-13)}$.

A investigação do mecanismo de produção do fonema sonoro também indicou o abaixamento da laringe durante a produção de fonemas plosivos sonoros como elemento funcional que permite a diminuição da tensão facilitando a sonorização ${ }^{(14)}$. Portanto, qualquer descontrole do funcionamento laríngeo poderia dificultar a sonorização. Pelo acoplamento da fonte glótica, as consoantes sonoras são menos intensas e mais graves do que suas correspondentes surdas ${ }^{(14)}$. Além desses, cinco outros fatores permitiriam a distinção entre essas consoantes: a força de articulação, o grau de aspiração, a transição dos formantes de vogais adjacentes, a duração da vogal precedente à plosiva e o Voice Onset Time $(\mathrm{VOT})^{(15)}$. O VOT foi definido como o intervalo entre a soltura articulatória da plosão e o início da vibração das pregas vocais. Várias pesquisas relacionaram o VOT às alterações vocais decorrentes de comprometimentos de mecanismos glóticos ${ }^{(2)}$. Outros pesquisadores acrescentaram que a análise do VOT é importante, tanto para a produção, como para a percepção da fala e ressaltaram que este tema foi discutido em vários estudos ${ }^{(16)}$.

Outro estudo revelou que há uma menor tendência à présonoridade no /g/ provavelmente porque é mais difícil, aerodinamicamente, a manutenção da sonoridade deste fonema devido ao reduzido volume supraglótico ${ }^{(17)}$.

Entretanto, o enfoque sobre a aquisição dos fonemas leva em conta a produção, assim como a recepção, a organização mental dos sons lingüísticos, fluência, estruturas e funções orais, aspectos supra-segmentais e voz ${ }^{(3)}$, o que mostra que o mecanismo vocal de produção da sonoridade não é o único elemento importante para a correta emissão do fonema sonoro. Os aspectos de familiaridade com a palavra, assim como sua estrutura, a posição tônica ou átona do fonema na palavra e o contexto fonético são variáveis importantes para o desenvolvimento da fala. Embora possa parecer que a presença ou ausência de vocalização durante a produção de uma consoante seja uma pista de fácil discriminação de sons, a real discriminação entre os cognatos fonemas surdos e sonoros, feita por ouvintes é uma tarefa complexa. Pode-se perceber, por meio do espectrograma de exemplos de fala, que as distinções entre a sonoridade ou vocalização estão associadas a diferentes padrões acústicos, dependendo do fonema e do local da palavra em que o contraste acontece ${ }^{(18)}$.

Mais recentemente, um estudo apontou que a análise acústica da fala de crianças com e sem transtorno fonológico permite verificar que algumas palavras, dependendo de seus contextos fonêmicos e fonéticos, facilitam mais que outras a produção, a percepção e, por fim o estabelecimento do contraste de sonoridade ${ }^{(19)}$.

A análise espectrográfica é cada vez mais utilizada como ferramenta diagnóstica no estudo dos transtornos fonológicos e a barra de sonoridade do VOT, a medida mais freqüentemente analisada, apesar da crescente importância conferida à medida de duração da vogal pós-consoante sonora, nos estudos do Português Brasileiro.

Nesta pesquisa, que estudou a fala de crianças disfônicas, a realização do estudo espectrográfico tomou como parâmetro para a identificação, do que na fala é produzido e percebido como ensurdecimento, apenas a ausência da barra de sonoridade anterior à soltura da oclusão da consoante plosiva, sendo esta indicativa da presença de vibração das pregas vocais com conseqüente produção do fonema sonoro. Não foram realizadas medidas temporais da barra de sonoridade, ou da duração da vogal precedente ou conseqüente à produção do fonema plosivo sonoro ou, ainda, caracterizada a transição dos formantes das vogais adjacentes ${ }^{(15,18-19)}$.

Estudos compararam este tipo de análise com a perceptivoauditiva $^{(19-22)}$. Com essa mesma finalidade constitui-se, nesta pesquisa, uma banca de fonoaudiólogos que julgaram, auditivamente, se a produção da criança era surda ou sonora.

A comparação da emissão de plosivas surdas e sonoras nas posições inicial e final, por meio da análise perceptivo-auditiva, em crianças com e sem transtorno fonológico indicou, em estudo americano maior número de erros percebidos nas consoantes plosivas sonoras em posição inicial ${ }^{(23)}$. Estudo realizado no Brasil encontrou maior incidência de ensurdecimento de fonemas plosivos velares e palatais do que labiais ${ }^{(5)}$.

As pistas acústicas para a distinção dos fonemas podem variar, também, de acordo com a posição da sílaba na palavra. A sílaba tônica sendo mais longa do que a átona permite que o ritmo da língua se construa em torno desta acentuação, a qual tem relação tanto com a intensidade quanto com a duração do som ${ }^{(24)}$. Uma vez que o acento tônico no Português Brasileiro tem relação com a possibilidade de maior nitidez do som produzido, facilitando o processo de sonorização e sua percepção, nesta pesquisa optou-se por investigar a sonoridade nas sílabas tônicas das palavras. Pesquisas encontraram maior sonorização nas sílabas tônicas do que nas átonas ${ }^{(20,22)}$.

A literatura científica brasileira não é pródiga em mostrar pesquisas que relacionem as alterações de voz àquelas de fala, ou vice-versa. Por isso, este estudo sobre o ensurdecimento na fala foi realizado sob a ótica das desordens vocais na infância.

Assim, os objetivos deste trabalho foram: caracterizar a fala de crianças disfônicas quanto à presença de ensurdecimentos na produção dos fonemas plosivos sonoros em sílabas tônicas, e estudá-la segundo variáveis de características dos fonemas, de sua localização na palavra e do tipo de análise de fala.

\section{MÉTODOS}

Esta pesquisa foi previamente aprovada pelo Comitê de Ética da Universidade Federal de São Paulo - UNIFESP, sob o protocolo $\mathrm{n}^{\circ} 0019 / 03$. Os responsáveis pelos sujeitos da pesquisa concordaram com sua realização e divulgação dos resultados, mediante assinatura do Termo de Consentimento Livre e Esclarecido.

Foram avaliadas amostras de fala de 40 crianças ( 22 meninos e 18 meninas) disfônicas, falantes do Português Brasileiro, sem queixas de alterações de fala, selecionadas no Ambulatório de Voz da Disciplina de Otorrinolaringologia Pediátrica 
da Universidade Federal de São Paulo, com idades variando entre quatro e oito anos. Todas apresentavam diagnóstico médico otorrinolaringológico e fonoaudiológico de disfonia funcional ou organo-funcional. Estas crianças constituíram o Grupo Disfônico (GD). O Grupo Controle (GC) foi formado por dez crianças (dois meninos e oito meninas) sem queixa fonoaudiológica de alterações vocais ou outras, por parte dos pais. Foram submetidos à avaliação perceptivo-auditiva da voz, cujos resultados confirmaram a ausência de queixas vocais. Assim como no GD, não foram realizadas avaliações da fala nesse grupo. A acuidade auditiva das 50 crianças foi avaliada e mostrou-se dentro dos padrões de normalidade.

Para a obtenção das amostras de fala foram solicitadas repetições de frases, constituídas por palavras que agruparam fonemas plosivos sonoros, segundo o ponto articulatório. Cada frase continha no máximo cinco palavras, de modo a possibilitar a repetição completa por parte da criança. Para o fonema /b/: "O Barbudo buzinou" e "Bia viu o bombom". Para o fonema /d/: "Daniel mordeu o dedo" e "Desenhei uma bandeira". Para o fonema /g/: "Os guardas nadam na lagoa" e "A mangueira dá manga".

As amostras de fala foram colhidas individualmente, em sala silenciosa, na presença do responsável pela criança. Cada gravação foi realizada em um único encontro. Solicitou-se a cada criança que repetisse, após ouvir a viva voz, as frases que reuniram os fonemas /b/, /d/ e /g/ (duas para cada fonema), totalizando seis frases. Todas as amostras de fala foram eliciadas e gravadas pela mesma examinadora, em minidisc (MD) JCV, com a utilização de um gravador digital Sony ${ }^{\circledR}$ MZ-R37, e microfone unidirecional Labtec $^{\circledR}$, localizado a aproximadamente $20 \mathrm{~cm}$ da boca da criança. Quando a criança não foi capaz de repetir a frase completa, esta foi novamente emitida pela examinadora, em número suficiente de vezes, de modo a garantir a completude da coleta das produções. Quando este procedimento foi utilizado, considerou-se como válida para análise, a última emissão de frase feita pela criança. As amostras de fala foram utilizadas em análises perceptivo-auditivas e espectrográficas para a investigação da presença de ensurdecimento na fala dessas crianças disfônicas. Somente as produções tônicas dos fonemas sonoros plosivos foram analisadas.

Para a análise perceptivo-auditiva das produções de fala foi constituída uma banca formada por três fonoaudiólogas (mínimo de 10 e média de 16 anos de atividade clínica). Cada fonoaudióloga recebeu: os MD que continham as gravações das repetições das 50 crianças, o mesmo gravador utilizado na coleta de dados, os fones de ouvido da marca Sony ${ }^{\circledR}$, acessórios do gravador, além de 50 protocolos, um para a análise de fala de cada criança. Também foi, individualmente, instruída a: a) ouvir, atentamente, a amostra de fala de cada criança; b) realizar, simultaneamente, a escuta de cada frase e a leitura da mesma no protocolo; c) assinalar no protocolo todas as alterações de fala que encontrasse, marcando graficamente na palavra escrita o(s) fonema(s) que percebesse alterado(s) e abaixo dele(s), como a produção foi percebida; d) ouvir a gravação de cada criança o número de vezes suficiente para se certificar do que ouviu; e) somente iniciar a análise de fala de outra criança quando finalizasse a anterior.

Cento e cinqüienta protocolos foram analisados e reunidos em uma planilha, cujas informações sobre ensurdecimento ou a produção correta do fonema foram baseadas na decisão de duas fonoaudiólogas quando não houve unanimidade.

Outras alterações de fala, como omissões ou substituições (baseadas em outros traços) foram percebidas auditivamente pela banca, assinaladas como erros, mas categorizadas de outra forma e não participaram no cômputo dos ensurdecimentos. Portanto, a partir desta análise, buscou-se quantificar somente as alterações identificadas pela banca relacionadas à percepção do ensurdecimento dos fonemas plosivos considerados ERROS, desprezando-se as demais (outras trocas).

A seguir, passou-se à análise espectrográfica das produções de fala para a qual se utilizou o programa Praat Versão 4.2.06 (25), instalado em um computador pessoal com processador Pentium 4 - 2.8. Para tanto, o gravador digital Sony ${ }^{\circledR}$ MZ-R37 foi conectado ao computador com um cabo P2 estéreo acessório do gravador digital. Abriu-se na tela, a cada vez, um arquivo de fala. Procedeu-se à busca, simultaneamente visual e auditiva, dos trechos de fala de cada criança desprezando-se as produções da examinadora. Congelada a imagem, buscouse novamente, a produção dos fonemas nas diversas posições tônicas das palavras pela associação da percepção auditiva da fala gravada e visual do espectrograma. Quando não foi possível identificá-los visualmente, reduziu-se ainda mais o intervalo, até a melhor visualização do espectro do fonema para obtenção da análise.

Para a análise espectrográfica da emissão dos fonemas plosivos sonoros, procurou-se a barra de sonoridade do VOT. Considerou-se, então a visualização da barra horizontal mais escura sob a produção da sílaba que continha o fonema a ser analisado como a barra de sonoridade. Marcou-se em outro protocolo, para cada criança, a produção de cada fonema como ACERTO: quando se buscou o fonema plosivo sonoro, em posição tônica inicial, medial, ou final e a barra de sonoridade foi visualizada anteriormente a espícula correspondente à plosão do fonema; e ERRO: quando a barra de sonoridade não esteve presente nas situações descritas acima.

A partir da primeira análise (perceptivo-auditiva) outras alterações de fala foram encontradas, descritas e classificadas como erro. Entretanto, foram desprezadas como objeto de estudo nesta pesquisa, uma vez que as crianças não apresentavam queixas relacionadas à presença de alterações de fala.

Para analisar os resultados utilizou-se o teste de Igualdade de Duas Proporções. Compararam-se os resultados da análise espectrográfica e perceptivo-auditiva de cada fonema plosivo sonoro, nas posições inicial, medial e final quanto à presença de ensurdecimento.

O resultado das comparações foi denominado p-valor e o nível de significância adotado foi de 0,05. As significâncias estatísticas foram marcadas com asterisco e as tendências à significância com \#.

\section{RESULTADOS}

Observa-se na Tabela 1 que, para todos os fonemas estudados, houve maior freqüência de ocorrência de acertos de produção do que erros de ensurdecimento. A comparação entre os resultados obtidos às duas análises mostra que, para todos 
os fonemas, a freqüência de ocorrência de erros na análise espectrográfica foi mais alta tanto no GD quanto no GC. Notase que houve diferença estatisticamente significante entre o desempenho do GD e do GC na emissão do fonema /b/, tanto na análise espectrográfica quanto na perceptivo-auditiva, com mais ensurdecimentos percebidos na fala do GD. O mesmo resultado estatisticamente significante foi observado na análise espectrográfica do fonema /d/. As análises do fonema /g/, não mostraram diferenças entre os grupos.

A Tabela 2 mostra a comparação dos resultados das análises perceptivo-auditiva e espectrográfica dos fonemas plosivos do GD, nas diferentes posições que os fonemas ocuparam na palavra. Na posição inicial, o fonema /b/, não determinou diferença de freqüência de ocorrência na identificação de erros, quando comparados os dois tipos de análise. A comparação entre os resultados das duas análises para os fonemas /d/ e $/ \mathrm{g} /$, evidenciou diferença estatisticamente significante, sendo o ensurdecimento mais frequientemente encontrado na análise espectrográfica. O estudo da posição medial, não mostrou diferença na comparação das análises dos fonemas plosivos sonoros /d/ e /g/ e apenas uma tendência à significância para o fonema $/ b /$, sendo mais alta a frequiência de ocorrência de

Tabela 1. Número de acertos, erros e de outras trocas dos fonemas sonoros na fala de criança segundo as análises espectrográfica e perceptivoauditiva e os grupos

\begin{tabular}{|c|c|c|c|c|c|c|c|c|c|c|}
\hline \multicolumn{3}{|c|}{ Fonema } & \multicolumn{4}{|c|}{ Espectrografia } & \multicolumn{4}{|c|}{ Perceptivo-auditiva } \\
\hline$/ \mathrm{b} /$ & GD & $\mathrm{N}$ & $\begin{array}{c}\text { Acertos } \\
86\end{array}$ & $\begin{array}{c}\text { Erros } \\
31\end{array}$ & $\begin{array}{c}\begin{array}{c}\text { Outras } \\
\text { trocas }\end{array} \\
3\end{array}$ & $\begin{array}{c}\text { Total } \\
120\end{array}$ & $\begin{array}{c}\text { Acertos } \\
98\end{array}$ & $\begin{array}{c}\text { Erros } \\
17\end{array}$ & $\begin{array}{c}\begin{array}{c}\text { Outras } \\
\text { trocas }\end{array} \\
5\end{array}$ & $\begin{array}{c}\text { Total } \\
120\end{array}$ \\
\hline & & $\%$ & 71,66 & 25,83 & 2,51 & 100 & 81,67 & 14,17 & 4,16 & 100 \\
\hline & GC & $\mathrm{N}$ & 29 & 1 & 0 & 30 & 30 & 0 & 0 & 30 \\
\hline & & $\%$ & 96,66 & 3,33 & 0 & 100 & 100 & 0 & 0 & 100 \\
\hline & $\mathrm{p}$-valor & & $0,004^{*}$ & $0,007^{*}$ & 0,382 & & $0,011^{*}$ & $0,029^{*}$ & 0,255 & \\
\hline \multirow[t]{5}{*}{$/ \mathrm{d} /$} & GD & $\mathrm{N}$ & 101 & 18 & 1 & 120 & 115 & 5 & 0 & 120 \\
\hline & & $\%$ & 84,16 & 15 & 0,84 & 100 & 95,84 & 4,16 & 0 & 100 \\
\hline & GC & $\mathrm{N}$ & 29 & 1 & 0 & 30 & 30 & 0 & 0 & 30 \\
\hline & & $\%$ & 96,66 & 3,33 & 0 & 100 & 100 & 0 & 0 & 100 \\
\hline & $\mathrm{p}$-valor & & $0,072^{*}$ & $0,086^{*}$ & 0,616 & & 0,255 & 0,255 & $-x-$ & \\
\hline \multirow[t]{5}{*}{ lg/ } & GD & $\mathrm{N}$ & 86 & 33 & 1 & 120 & 113 & 6 & 1 & 120 \\
\hline & & $\%$ & 71,66 & 27,5 & 0,84 & 100 & 94,16 & 5 & 0,84 & 100 \\
\hline & GC & $\mathrm{N}$ & 24 & 6 & 0 & 30 & 30 & 0 & 0 & 30 \\
\hline & & $\%$ & 92,5 & 7,5 & 0 & 100 & 100 & 0 & 0 & 100 \\
\hline & $\mathrm{p}$-valor & & 0,356 & 0,402 & 0,616 & & 0,175 & 0,211 & 0,616 & \\
\hline
\end{tabular}

Legenda: N=número de ocorrências; \%= porcentagem; GD =Grupo disfônico; GC=Grupo Controle; * estatisticamente significante (p-valor < 0,05)

Tabela 2. Distribuição de acertos e erros de ensurdecimento dos fonemas plosivos nas posições inicial média e final quanto às análises espectrográfica e perceptivo-auditiva no GD

\begin{tabular}{|c|c|c|c|c|c|c|c|}
\hline \multirow{3}{*}{ Fonema } & \multicolumn{2}{|c|}{ Grupo Disfônico } & \multicolumn{4}{|c|}{ Resultado das análises } & \multirow{3}{*}{$\mathrm{p}$-valor } \\
\hline & \multirow[t]{2}{*}{ Posição da Tônica } & \multirow[t]{2}{*}{ Tipo de Análise } & \multicolumn{2}{|c|}{ Acertos } & \multicolumn{2}{|c|}{ Erros } & \\
\hline & & & $\mathrm{N}$ & $\%$ & $\mathrm{~N}$ & $\%$ & \\
\hline \multirow[t]{6}{*}{$/ \mathrm{b} /$} & Ini & Espectro & 24 & 60 & 16 & 40 & 0,644 \\
\hline & & Perc Aud & 26 & 65 & 14 & 35 & \\
\hline & Med & Espectro & 33 & 82,5 & 7 & 17,5 & 0,077\# \\
\hline & & Perc Aud & 38 & 95 & 2 & 5 & \\
\hline & Fin & Espectro & 31 & 77,5 & 9 & 22,5 & $0,023^{*}$ \\
\hline & & Perc Aud & 38 & 95 & 2 & 5 & \\
\hline \multirow[t]{6}{*}{$/ d /$} & Ini & Espectro & 31 & 77,5 & 9 & 22,5 & $0,023^{*}$ \\
\hline & & Perc Aud & 38 & 95 & 2 & 5 & \\
\hline & Med & Espectro & 37 & 92,5 & 3 & 7,5 & 0,644 \\
\hline & & Perc Aud & 38 & 95 & 2 & 5 & \\
\hline & Fin & Espectro & 34 & 85 & 6 & 15 & $0,048^{*}$ \\
\hline & & Perc Aud & 39 & 97,5 & 1 & 2,5 & \\
\hline \multirow[t]{5}{*}{$/ g /$} & Ini & Espectro & 27 & 67,5 & 13 & 32,5 & $<0,001^{*}$ \\
\hline & & Perc Aud & 40 & 100 & 0 & 0 & \\
\hline & Med & Espectro & 36 & 90 & 4 & 10 & 0,396 \\
\hline & & Perc Aud & 38 & 95 & 2 & 5 & \\
\hline & Fin & Espectro & 25 & 62,5 & 15 & 37,5 & $0,004^{*}$ \\
\hline
\end{tabular}

Legenda: Espectro = análise espectrográfica; Perc Aud = Análise perceptivo auditiva; Ini = Posição inicial; Med = Posição medial; Fin = Posição final; ${ }^{\star}$ estatisticamente significante ( $p$-valor < 0,05); \# tendência à significância estatística 
ensurdecimentos encontrados na análise espectrográfica. A comparação em posição final mostrou diferença significante, sendo maior o número de erros encontrados na análise espectrográfica para os três fonemas.

Na Tabela 3 pode ser observada a comparação dos resultados das análises perceptivo-auditiva e espectrográfica dos fonemas plosivos do GC, nas diferentes posições que os fonemas ocuparam na palavra. Nas análises das posições inicial, medial e final não foi observada diferença estatisticamente significante entre as freqüências de ensurdecimentos observadas na espectrografia pela percepção auditiva para os fonemas /b/ e /d/ e /g/ com exceção deste último para o qual foram percebidos mais ensurdecimentos na posição medial na análise espectrográfica.

Tabela 3. Distribuição de acertos e erros de ensurdecimento dos fonemas plosivos nas posições inicial média e final quanto às análises espectrográfica e perceptivo-auditiva no GC

\begin{tabular}{llccccc}
\hline \multirow{2}{*}{$\begin{array}{llccc}\text { Grupo Controle } \\
\text { Posição da }\end{array}$} & Tipo de & \multicolumn{3}{c}{ Resultado das análises } & \\
\cline { 2 - 5 } Tônica & Análise & $\mathrm{N}$ & $\%$ & $\mathrm{~N}$ & $\%$ & \\
\hline Ini & Espectro & 10 & 100 & 0 & 0 & $-\mathrm{x}-$ \\
& Perc Aud & 10 & 100 & 0 & 0 & \\
Med & Espectro & 9 & 90 & 1 & 10 & 0,305 \\
& Perc Aud & 10 & 100 & 0 & 0 & \\
Fin & Espectro & 10 & 100 & 0 & 0 & $-\mathrm{x}-$ \\
& Perc Aud & 10 & 100 & 0 & 0 & \\
Ini & Espectro & 9 & 90 & 1 & 10 & 0,305 \\
& Perc Aud & 10 & 100 & 0 & 0 & \\
Med & Espectro & 10 & 100 & 0 & 0 & $-\mathrm{x}-$ \\
& Perc Aud & 10 & 100 & 0 & 0 & \\
\multirow{2}{*}{ Fin } & Espectro & 10 & 100 & 0 & 0 & $-\mathrm{x}-$ \\
& Perc Aud & 10 & 100 & 0 & 0 & \\
Ini & Espectro & 8 & 80 & 2 & 20 & $0,136 \#$ \\
& Perc Aud & 10 & 100 & 0 & 0 & \\
Med & Espectro & 6 & 60 & 4 & 40 & $0,025^{*}$ \\
\hline
\end{tabular}

Legenda: Espectro = Análise espectrográfica; Perc Aud = Análise perceptivo auditiva; Ini = Posição inicial; Med = Posição medial; Fin = Posição final; * estatisticamente significante ( $p$-valor $<0,05)$; \# tendência à significância estatística

A Tabela 4 analisa comparativamente o número de ensurdecimentos, percebidos por meio da espectrografia e da percepção auditiva, nas produções do GD com as do GC, de cada fonema, nas três posições da palavra.

Não houve diferença estatística ao se comparar a freqüência de erros do fonema /d/ dos dois grupos, nos dois tipos de análise, em qualquer posição na palavra. A análise do fonema /g/ mostrou que maior número de ensurdecimentos pode ser identificado na produção do fonema em posição medial pelo GC, por meio da análise espectrográfica. Além disso, a análise do mesmo fonema $(/ \mathrm{g} /)$ mostrou maior número de erros detectado no GD, na posição final, também por meio da análise espectrográfica. A análise da produção do fonema /b/, comparando-se as análises espectrográfica e perceptivo-auditiva dos dois grupos, mostra maior freqüência de ensurdecimentos percebidos na posição inicial da produção do GD em relação ao GC nos dois tipos de análise. $\mathrm{O}$ mesmo resultado foi encontrado na análise comparativa da posição final dos dois grupos na sendo novamente maior o número de erros percebido para o GD na análise espectrográfica.

Tabela 4. Comparação dos GD e GC quanto ao número de erros dos fonemas plosivos nas posições inicial, medial e final nas análises espectrográfica e perceptivo-auditiva

\begin{tabular}{lccc}
\hline Fonema & $\begin{array}{c}\text { Posição da } \\
\text { Tônica }\end{array}$ & Tipo de Análise & p-valor \\
\hline /b/ & Ini & Espectro & $0,015^{*}$ \\
& Med & Perc Aud & $0,027^{*}$ \\
& Fin & Perc Aud & 0,470 \\
& & Espectro & $0,098^{*}$ \\
/d/ & Perc Aud & 0,470 \\
& Ini & Espectro & 0,377 \\
& Med & Perc Aud & 0,470 \\
& & Espectro & 0,372 \\
& Fin & Perc Aud & 0,470 \\
& & Espectro & 0,192 \\
& & Perc Aud & 0,614 \\
& Ini & Espectro & 0,440 \\
& & Perc Aud & $-\mathrm{x}-$ \\
& Med & Espectro & $0,021^{*}$ \\
& & Perc Aud & 0,470 \\
& Fin & Espectro & $0,021^{*}$ \\
& & Perc Aud & 0,297 \\
\hline
\end{tabular}

Legenda: Espectro $=$ Análise espectrográfica; Perc Aud = Análise perceptivo auditiva; Ini = Posição inicial; Med = Posição medial; Fin = Posição final; * ${ }^{\text {es- }}$ tatisticamente significante $(p$-valor $<0,05)$

\section{DISCUSSÃO}

Para a obtenção das amostras de fala foram selecionadas crianças disfônicas a partir de quatro anos. Nesta idade, crianças falantes do Português Brasileiro já adquiriram e estabilizaram o uso dos fonemas plosivos e fricativos surdos e sonoros $^{(7,26-28)}$. Os ensurdecimentos foram analisados apenas quanto à produção. Não foram realizados quaisquer estudos ou análises sobre questões fonológicas. Por isso outras alterações de fala, percebidas nas produções das crianças disfônicas, não foram estudadas. Tampouco se considerou a possibilidade de haver alterações no processamento da informação auditiva. Neste estudo, contou-se apenas com a informação da normalidade dos resultados audiométricos.

Esta pesquisa foi realizada sob a ótica da disfonia, por ser esta uma patologia de alta prevalência, atingindo de 6 a $9 \%$ da população infantil ${ }^{(12,29)}$ e pelo fato de não ser rara a percepção de alterações vocais em crianças com distúrbios de fala.

O estudo espectrográfico tomou como parâmetro para a identificação do que na fala é produzido e percebido como ensurdecimento, apenas a ausência da barra de sonoridade anterior à soltura da oclusão da consoante plosiva. A descon- 
sideração dos demais parâmetros como duração e transição dos formantes de vogais adjacentes não permitiu tecer considerações sobre o conhecimento da criança acerca do traço de sonoridade. Por outro lado, nenhuma das crianças disfônicas da amostra apresentou $100 \%$ de ensurdecimentos e, portanto, estes teriam sido dados irrelevantes para o alcance do objetivo inicialmente traçado nesta pesquisa.

De fato, para todos os fonemas estudados, houve maior freqüência de ocorrência de acertos de produção do que erros de ensurdecimento em ambos os grupos. Apesar disso, foi possível observar que a análise espectrográfica identificou maior número de ensurdecimentos do que a perceptivo-auditiva, tanto no grupo de crianças disfônicas quanto no GC (Tabela 1), resultado que vai de encontro à literatura ${ }^{(29-30)}$.

A análise comparativa de cada fonema sonoro mostrou que mais ensurdecimentos foram percebidos na produção do fonema /b/ das crianças disfônicas, quando comparadas ao GC tanto na análise espectrográfica quanto na perceptivo-auditiva. Diferença estatisticamente significante também foi observada na análise espectrográfica do fonema /d/ com mais ensurdecimentos na fala dos disfônicos. Apenas a análise do fonema $/ \mathrm{g} /$, não evidenciou diferenças entre os grupos.

De uma maneira geral, este estudo mostrou que as crianças disfônicas produziram maior número de erros, percebidos como ensurdecimentos do que as não disfônicas. A alteração da produção vocal se não determinou, ao menos influenciou esse resultado pela alteração da dinâmica de vibração das pregas vocais ${ }^{(2)}$. Pesquisa anteriormente realizada mostrou que crianças que ensurdecem na fala têm falta de controle laríngeo e têm a freqüência fundamental mais grave, característica da rouquidão e soprosidade apresentadas pelas crianças deste estudo $^{(9,11)}$. Resultado de outra pesquisa realizada no Brasil encontraram em $50 \%$ das crianças com queixa de fala, também a presença de queixas vocais ${ }^{(4)}$.

Quando se analisaram as produções das crianças disfônicas, levando-se em conta a posição da sílaba tônica na palavra (Tabela 2), percebeu-se menor número de ensurdecimentos nas sílabas tônicas em posição medial, para os três fonemas plosivos sonoros, tanto na análise espectrográfica quanto na perceptivo-auditiva, não sendo identificadas diferenças entre os resultados das duas análises. Estes resultados indicam que a sonoridade nos fonemas plosivos seja facilitada pela maior força e nitidez com que são produzidos em sílaba tônica na posição medial ${ }^{(24)}$. Estudos realizados confirmaram que na sílaba tônica há maior sonorização ${ }^{(20,22)}$. Sendo assim, a identificação clínica do ensurdecimento pode ser dificultada se o fonema a ser analisado estiver em ambiente sonoro de sílaba medial e em condição de maior tonicidade na palavra.

A produção do fonema /b/ em sílaba tônica inicial mostrou maior número de ensurdecimentos identificados, independentemente do tipo de análise, quando comparados àqueles das produções nas demais posições silábicas para esse fonema e às produções dos demais fonemas. Ou seja, as crianças disfônicas produziram maior número de ensurdecimentos - também percebidos pela análise auditiva - quando falaram palavras iniciadas com /b/ em sílaba tônica inicial.

Ensurdecimentos também foram identificados na produção dos fonemas $/ \mathrm{d} / \mathrm{e} / \mathrm{g} / \mathrm{na}$ sílaba tônica em posição inicial e final, e do /b/ na posição final, porém com maior número de identificações pela espectrografia em relação à capacidade de percepção auditiva, sendo estas diferenças, estatisticamente significantes. Estes resultados mostram que a identificação perceptivo-auditiva do ensurdecimento na produção de sons plosivos sonoros pode ser dificultada se o fonema a ser analisado está em sílaba final. A maior diferença foi encontrada na análise do fonema $/ \mathrm{g} / \mathrm{em}$ sílaba tônica, no início da palavra a qual mostrou que nenhum ensurdecimento foi identificado auditivamente, enquanto $32,5 \%$ foram encontrados à espectrografia, confirmando os resultados da Tabela 1. Estudo realizado com crianças sem alterações vocais também encontrou maior incidência de ensurdecimento nos fonemas velares e palatais ${ }^{(5)}$.

O estudo comparativo entre a análise espectrográfica e a perceptivo-auditiva da fala das crianças do GC (Tabela 3), não mostrou diferença para os fonemas /b/e /d/ em nenhuma das três posições da sílaba na palavra. Os ensurdecimentos identificados o foram pela análise espectrográfica, em sílaba inicial ou medial. Ao contrário do que foi observado nas crianças disfônicas, maior número de ensurdecimentos foi encontrado nas produções do fonema /g/ nas posições: inicial e medial. Entretanto, somente a análise espectrográfica identificou esses erros. De fato, há menor pré-sonoridade na produção de um som velar o que pode explicar a maior ocorrência de ensurdecimentos desse fonema na amostra de crianças sem alterações vocais ${ }^{(5,17)}$.

Comparando-se os resultados mostrados na Tabela 4, foi possível perceber que na posição inicial o fonema /b/ foi mais ensurdecido na produção das crianças disfônicas do que na das crianças sem alterações vocais, sendo mais identificado tanto na análise espectrográfica quanto na perceptivo-auditiva. A análise espectrográfica também identificou maior número de ensurdecimentos na fala das crianças disfônicas, quando comparada à das crianças sem alterações vocais, na produção dos fonemas $/ \mathrm{b} / \mathrm{e} / \mathrm{g} /$, em sílaba tônica no final da palavra. Por outro lado, a produção do /g/ em sílaba tônica na posição medial mostrou maior porcentagem de ensurdecimentos identificados na fala das crianças sem alterações vocais à espectrografia, quando comparadas com as produções disfônicas.

As demais produções de fala analisadas, não mostraram diferenças entre os grupos de crianças. A comparação da produção do fonema /d/ não indicou diferença entre os dois grupos, qualquer que tenha sido o tipo de análise realizada. Apesar de não ter sido evidenciada diferença estatisticamente significante, a observação das porcentagens de ensurdecimento mostrou maior número de ocorrências de erros na fala das crianças disfônicas.

Não foram encontrados, na literatura compulsada trabalhos que, semelhantemente a este, tenham investigado comparativamente a presença de ensurdecimentos na fala de crianças disfônicas e crianças sem alterações vocais, todas sem queixas de alterações de fala. Desta forma, não foi possível confrontar os resultados encontrados.

Entretanto, há pesquisas que apontam a presença de vibrações irregulares decorrentes das alterações das pregas vocais das crianças disfônicas que podem justificar a dificuldade de sonorização das consoantes plosivas sonoras na fala dessas crianças ${ }^{(9-11,18)}$. 
Os resultados desta pesquisa mostraram a presença de ensurdecimento na fala de crianças disfônicas com maior freqüência de ocorrência do que na fala de crianças sem queixas vocais. $\mathrm{O}$ ensurdecimento foi encontrado com maior frequiência na análise espectrográfica do que na perceptivoauditiva e esteve presente com maior freqüência em sílabas tônicas nas posições: inicial e final de palavras produzidas em fala encadeada. Deve-se lembrar que, apesar dos resultados encontrados, nenhuma das crianças disfônicas desta pesquisa apresentou queixa relacionada a alterações de fala. Estes resultados também sugerem que a alteração vocal pode influenciar o padrão de sonoridade na produção dos fonemas sonoros sem, no entanto, interferir nas demais características acústicas de duração ou intensidade de vogais subseqüentes ou precedentes, por exemplo, também observadas nas diferenciações entre fonemas surdos e sonoros. $\mathrm{O}$ fato da análise perceptivo-auditiva ter identificado menos ensurdecimentos do que a espectrográfica pode ter sofrido essa influência ${ }^{(19)}$.

Apesar de ser conhecido o fato de que o mecanismo vocal de produção da sonoridade não ser o único elemento importante para a correta emissão do fonema sonoro, o cuidado com a identificação de ensurdecimentos em crianças disfônicas ou de alterações vocais, ainda que leves, em crianças que trocam letras ao ler e escrever deve ser tomado. Pesquisas que investiguem a influência dessas características de fala de crianças disfônicas sobre seu aprendizado e produção de escrita e leitura devem ser incentivadas e realizadas.

Os resultados desta pesquisa também mostraram que a escolha do item ou estímulo lingüístico, realmente, pode influenciar a respostas do paciente ${ }^{(18-19)}$, o que demonstra o cuidado que o avaliador deve tomar ao elaborar um protocolo ou ao realizar o exame fonoaudiológico de voz ou fala.

\section{CONCLUSÃO}

A análise crítica dos resultados obtidos por meio das avaliações espectrográfica e perceptivo-auditiva da fala de crianças disfônicas comparada a um grupo de crianças sem queixas vocais para caracterizar a ocorrência de ensurdecimentos, permitiu concluir que: o ensurdecimento foi identificado de forma assistemática, em maior ou menor número, na produção dos fonemas plosivos sonoros dos dois Grupos estudados; os dois tipos de análise de fala identificaram o ensurdecimento na produção dos fonemas plosivos sonoros sendo que a análise espectrográfica identificou maior número de ocorrências do que a análise perceptivo-auditiva. No grupo de crianças disfônicas foi identificado o ensurdecimento dos três fonemas plosivos sonoros enquanto que no grupo de crianças sem alterações vocais a identificação se deu apenas para o fonema /g/ em posição tônica na sílaba medial. O maior número de ensurdecimentos foi encontrado nas posições tônicas: inicial e final das palavras.

\begin{abstract}
Purpose: To characterize the occurrence of plosive sounds' devoicing in the speech of dysphonic children. Methods: Fifty children with ages between four and eight years old (40 dysphonic and ten without any vocal disorders) were recorded repeating six sentences containing plosive phonemes in initial, medial and final tonic positions. Both spectrographic and auditory-perceptual analyses were carried out. Results: Devoicing of plosive phonemes occurred unsystematically. It was more identified in the spectrographic analysis, and varied according to the phoneme and its position in the word. Conclusion: The speech of both dysphonic children and children without vocal disorders presented unsystematic substitution of voiced by voiceless plosive phonemes. The substitutions were less frequent when the phoneme occurred in medial tonic position.
\end{abstract}

KEYWORDS: Speech; Voice disorders; Speech disorders; Speech acoustics; Child

\section{REFERÊNCIAS}

1. Walsh T, Parker F. A review of the vocalic cues to $[ \pm$ voice] in postvocalic stops in English. J Phonetics. 1984; 12: 207-18.

2. Camargo Z, Madureira S. Análise acústica: revisão crítica de estudos no campo das disfonias. In: Ferreira LP, Befi-Lopes DM, Limongi SCO, organizadores. Tratado de fonoaudiologia. São Paulo: Editora Roca; 2004. p. 25-33.

3. Pagan LO, Wertzner HF. Intervenção no distúrbio fonológico por meio dos pares mínimos com oposição máxima. Pró-Fono. 2002;14(3):313-24.

4. Franco DP, Avila CRB. Achados fonoaudiólogos de crianças com queixa de distúrbio de fala. Pró-Fono. 2000;12(1):40-7.

5. Gurgueira AL. Estudo acústico dos fonemas surdos e sonoros do Português do Brasil, em crianças com distúrbio fonológico apresentando o processo fonológico de ensurdecimento [dissertação]. São Paulo: Faculdade de Filosofia, Letras e Ciências Humanas da Universidade de São Paulo; 2000.
6. Mota HB, Keske-Soares M, Bagetti T, Vieira MG, Ceron MI. Incidência do desvio fonológico associado ou não a outras alterações em sujeitos atendidos em serviço de atendimento fonoaudiológico. In: Congresso Brasileiro de Fonoaudiologia; 2004 Out 6-9; Foz do Iguaçu. Anais. São Paulo; 2004.

7. Galea DES, Wertzner HF. O processo fonológico de ensurdecimento em crianças em desenvolvimento fonológico típico. In: Congresso Brasileiro de Fonoaudiologia; 2004 Out 6-9; Foz do Iguaçu. Anais. São Paulo; 2004.

8. Wertzner HF, Pagan LO, Galea DES, Papp ACCS. Características fonológicas de crianças com transtorno fonológico com e sem histórico de otite média. Rev Soc Bras Fonoaudiol. 2007;12(1):41-7.

9. Brasolotto A, Behlau M. Vocal Assesment of children who substitute voiced phonemes by voiceless phonemes acoustic and diadochokinetic analysis. In: Behlau M, organizador. Laringologia e voz hoje: Temas do IV Congresso Brasileiro de Laringologia e Voz. Rio de Janeiro: Revinter; 1998. p.397-8. 
10. Behlau MS, Gonçalves MI. Considerações sobre a Disfonia Infantil. In: Ferreira LP, organizador. Trabalhando a voz: vários enfoques em fonoaudiologia. São Paulo: Summus; 1988. p. 99-107.

11. Haydée HF, Gurgueira AL, Pagan LO. Medidas de VOT dos fonemas /p/ e /b/ do português brasileiro relacionados à distinção do traço de sonoridade. In: Congresso Brasileiro de Fonoaudiologia; 2004 Out 6-9; Foz do Iguaçu. Anais. São Paulo; 2004.

12. Wuyts FL, Heylen L, Mertens F, Du Caju M, Rooman R, Van de Heyning PH, De Bodt M. Effects of age, sex, and disorder on voice range profile characteristics of 230 children. Ann Otol Rinol Laryngol. 2003;112(6):540-8.

13. Carding PN, Roulstone S, Northstone K; ALSPAC Study Team. The prevalence of childhood dysphonia: a cross-sectional study. J Voice. 2006;20(4):623-30.

14. Gielow I. Análise espectrográfica da zona de transição dos formantes das vogais subsequientes aos sons plosivos do Português Brasileiro. [monografia de especialização]. São Paulo: Universidade Federal de São Paulo. Escola Paulista de Medicina; 1993

15. Russo ICP, Behlau M. Percepção da fala: análise acústica do Português Brasileiro. São Paulo: Editora Lovise; 1993

16. Whiteside SP, Marshall J. Developmental trends in voice onset time: some evidence of sex differences. Phonetica. 2001;58(3):196-210

17. Behlau MS, Pontes PAL, Tosi O, Ganança MM. Análise do tempo de início de sonorização dos sons plosivos do português. Acta AWHO. 1988;7(2):86-97.

18. Yeni-Komshian GH. Speech perception. In: Gleason JB, Ratner NB, editors. Psycholinguistics. 2nd ed. Fort Worth: Harcourt Brace College Publishers; 1998. chap 3. p. 108-56.

19. Gurgueira AL. Estudo acústico do "voice onset time" e da duração da vogal na distinção da sonoridade dos sons plosivos em crianças com transtorno fonológico. [tese doutorado]. São Paulo: Faculdade de Filosofia Letras e Ciências Humanas da Universidade de São Paulo; 2006.
20. Brito AT, Magalhães JO. Análise fonético-fonológica do desvozeamento de obstruintes. In: Congresso Brasileiro de Fonoaudiologia; 2003 Out 1-4; Fortaleza; Anais. São Paulo; 2003.

21. Sader RCM, Hanayama EM. Considerações teóricas sobre a abordagem acústica da voz infantil. Rev CEFAC. 2004;6(3):312-8.

22. Sanches AP, Roncari JRA, Sanches SF. Análise espectrográfica da fala de crianças disfônicas com trocas grafêmicas nos plosivos surdos e sonoros. In: Congresso Brasileiro de Fonoaudiologia; 2004 Out 6-9; Foz do Iguaçu. Anais. São Paulo; 2004.

23. Catts HW, Jensen PJ. Speech timing of phonologically disordered children: voicing contrast of initial and final stop consonants. J Speech Hear Res. 1983;26(4):501-10.

24. Bechara E. Moderna gramática portuguesa. 37a ed. Rio de Janeiro: Lucerna; 2002.

25. Boersma P, Weenik D. Praat [computer program]. Versão 4.2.06 Amsterdã; 1992-2003.

26. Befi-Lopes DM, Gândara JP, Araújo K. Aquisição do sistema fonológico em crianças com alterações no desenvolvimento da linguagem. PróFono. 2003;15(1):19-30.

27. Keske-Soares M, Blanco APF, Mota HB. O desvio fonológico caracterizado por índices de substituição e omissão. Rev Soc Bras Fonoaudiolol. 2004;9(1):10-8.

28. Lamprecht RR, Bonilha GFG, Freitas GCM, Matzenauer CLB, Mezzomo CL, Oliveira CC, Ribas LP. Aquisição fonológica do português: perfil de desenvolvimento e subsídios para terapia. Porto Alegre: Artmed; 2004

29. Martins RHG, Trindade SHK. A criança disfônica: diagnóstico, tratamento e evolução clínica. Rev Bras Otorrinolaringol. 2003;69(6):801-6.

30. Gregio FN, Camargo ZA. Dados de tempo de início do vozeamento (VOT) na avaliação do sinal vocal de indivíduos com paralisia unilateral de prega vocal. Disturb Comun. 2005;17(3):289-97. 